Bio-grafía. Escritos sobre la Biología y su Enseñanza. ISSN 2027-1034

Número Extraordinario. p.p. $40-54$

Memorias del Primer encuentro ambiental Universidad, ambiente y sustentabilidad: experiencias y prácticas.

\title{
RECONOCIMIENTO DE SABERES DE LA COMUNIDAD SOBRE EL MANGLAR Y LA PESCA DESDE EL CONTEXTO DE BOCAS DE SATINGA-NARIÑO.
}

\author{
Lina Julieth Arias Merchán ${ }^{1}$ \\ Karen Lorena Angulo Quiñones²
}

\section{Resumen}

Este trabajo de investigación es el resultado de la práctica pedagógica integral que se realizó en la Institución Educativa Comercial Litoral Pacífico en la cabecera municipal Bocas de Satinga (Nariño), en el segundo semestre del año 2015, con los estudiantes de grado tercero y cuarto de primaria de la jornada mañana, con el objetivo de identificar sus concepciones acerca de la memoria biocultural asociado al ecosistema de manglar y pesca artesanal generando aportes a la enseñanza-aprendizaje de la biología. Desde el enfoque de la pedagogía en contexto adaptado de Peña M. (2013) se abordaron distintas actividades y estrategias didácticas que motivaran espacios de diálogo para el conocimiento de estas concepciones. Para la recolección de la información se tuvo en cuenta instrumentos como el cuaderno de campo, medios audiovisuales (Fotografías, videos y grabaciones) y técnicas como entrevistas, salidas pedagógicas y observación participante en la comunidad. Los resultados y el análisis que se presentan durante este artículo dan cuenta de una experiencia personal y profesional enriquecedora, abordando saberes, reflexiones asociadas a el lugar de la educación ambiental en contextos bioculturalmente diversos; reconociendo las creencias y prácticas propias del pacífico que surgen desde las raíces más profundas de sus ancestros

\footnotetext{
${ }^{1}$ Universidad Pedagógica Nacional. Estudiante de la Licenciatura en Biología. dbi_larias814@pedagogica.edu.co

${ }^{2}$ Universidad Pedagógica Nacional. Estudiante de la Licenciatura en Biología. dbi_kangulo938@pedagogica.edu.co
} 
Bio-grafía. Escritos sobre la Biología y su Enseñanza. ISSN 2027-1034

Número Extraordinario. p.p. $40-54$

Memorias del Primer encuentro ambiental Universidad, ambiente y sustentabilidad: experiencias y prácticas.

afrocolombianos, dando luz y vida a una comunidad que a pesar de las problemáticas ambientales, sociales, económicas, etc., se mantienen como un pueblo unido que valora y respeta su cultura, mostrando espacios donde el ser en una expresión de color, sabor, alegría, olor y aún más importante de memoria.

Palabras Clave: Concepciones, Ecosistema de manglar, Pesca artesanal, Memoria Biocultural, Pedagogía en contexto.

\section{Abstract}

This research is the result of comprehensive teaching practice held in the Educational Institution Commercial Pacific Coast in the municipal head Bocas de Satinga (Nariño), in the second half of 2015, with students in third grade and fourth primary of the day tomorrow, with the aim of identifying their conceptions about the biocultural memory associated with the mangrove ecosystem and fishing, generating contributions in teaching and learning of biology. From the perspective of pedagogy in context adapted from Peña M. (2012) different activities and teaching strategies that motivate dialogue spaces for knowledge of these concepts they were discussed. To collect information was considered instruments such as the field notebook, media (pictures, videos and recordings) and techniques such as interviews, educational outings and community participant observation. The results and analysis presented in this article realize a personal and professional experience addressing knowledge, reflections associated with the place of environmental education in bioculturally different contexts; recognizing own beliefs and practices Pacific emerging from the deepest roots of the Afro-Colombian ancestors, giving light and life to a community that despite its problems remain as a united people that values and 
Bio-grafía. Escritos sobre la Biología y su Enseñanza. ISSN 2027-1034

Número Extraordinario. p.p. $40-54$

Memorias del Primer encuentro ambiental Universidad, ambiente y sustentabilidad: experiencias y prácticas.

respects their culture, showing spaces where being it is an expression of color, flavor, joy, and even more importantly memory.

Keywords: Conceptions, mangrove Ecosystem, Artisanal fisheries, Biocultural Memory, Pedagogy in context.

\section{INTRODUCCIÓN}

La experiencia nace desde el contacto con la vida, con las vivencias, colores, e historias que se construyen en la relación con los otros, el diálogo, el reconocimiento y la expresión de lo vivo. Para esta investigación ha sido importante reflexionar que la historia de nuestro país ha sido marcada por episodios

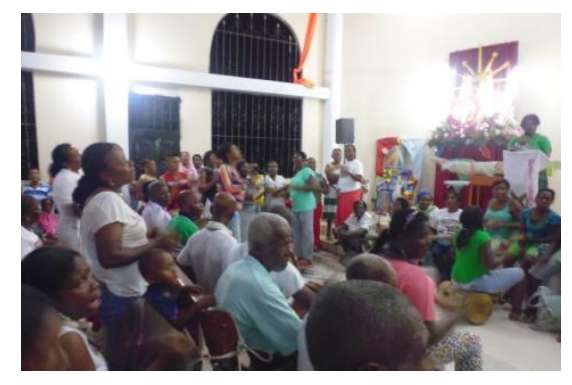

Foto 1. Fiestas patronales. Angulo K. (2015) de violencia y desarraigo, donde departamentos como Nariño, presenta descuidos por parte del Estado, así como serias problemáticas ambientales, educativas, sociales y de conflicto armado, causando que familias afrocolombianas, indígenas, campesinas, entre otras, tengan que adaptarse a condiciones poco favorables para su calidad de vida. Estas circunstancias, hacen que el maestro y la escuela cobren un mayor sentido, partiendo desde contextos tan diversos como este, donde se construye conocimientos y estrategias que respondan a las necesidades de la comunidad y del territorio.

En este sentido, este trabajo tuvo lugar en el departamento de Nariño, específicamente en el Municipio Olaya Herrera, la cabecera municipal Bocas de Satinga. Este territorio pertenece a la región de la llanura del Pacífico, caracterizándose por las altas temperaturas, las abundantes lluvias y exuberante vegetación; se pueden distinguir subregiones como el Andén Aluvial o Zona de Mangle. Satinga, como le dicen sus pobladores se 
Bio-grafía. Escritos sobre la Biología y su Enseñanza. ISSN 2027-1034

Número Extraordinario. p.p. $40-54$

Memorias del Primer encuentro ambiental Universidad, ambiente y sustentabilidad: experiencias y prácticas.

caracteriza por vivir sobre el agua, de ahí provienen dinámicas como la pesca, extracción de madera, comercio por vía acuática, agricultura, etc., que tienen como aspecto principal el rio, quien les provee todos los recursos necesarios para su subsistencia. Así mismo, su cultura afrocolombiana los hace poseedores de prácticas, creencias y saberes ancestrales únicos en esta zona del pacífico. Se observa como una sociedad viva, alegre que han logrado mantener procesos de identidad cultural, por su danza, el canto, el baile y su folclor como construcción de valores que combinan todo un universo cultural amplio y complejo, como estrategia de vida. (INELPAC, 1997 pág. 7).

A partir de estos aspectos que identifican al municipio, es importante reconocer algunas problemáticas que nacen desde las pocas iniciativas y oportunidades de transformación que inciden en los factores socioculturales, socio ambientales y socioeducativas de la región como la carencia de servicios públicos (gas, agua, luz, etc.,), la descontextualización en procesos y actividades educativas en las instituciones, la contaminación de los ríos, pesca indiscriminada, tala del ecosistema de manglar, perdida de saberes ancestrales, deficiente salubridad en la zona, intervención de cultivos ilícitos (narcotráficos) y conflicto armado, entre otras problemáticas que hacen que este contexto necesite soluciones y nuevas estrategias para su población y su territorio.

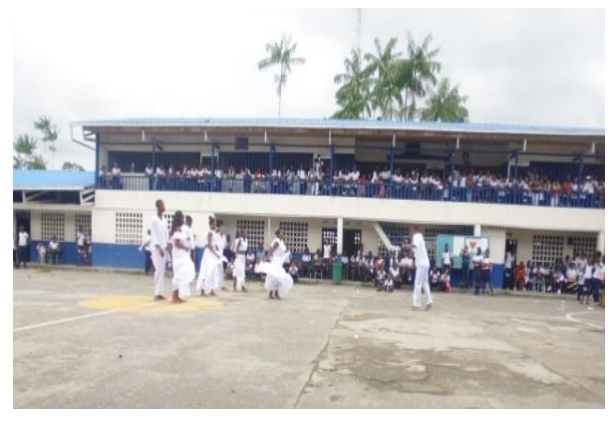

Imagen 2. Evento cultural. INELPAC. Angulo K. (2015)

Partiendo de esto, la investigación se encontró enfocada en el acercamiento de los estudiantes de tercero y cuarto grado de primaria en la Institución Educativa Comercial Litoral Pacífico (INELPAC), la cual acoge a gran cantidad de niños y jóvenes, teniendo como propósito una educación que respete las diferencias desde la formación integral del educando en el "desarrollo de un currículo dinámico, abierto, flexible y pertinente” (INELPAC, 1997 pág. 12), que da lugar 
Bio-grafía. Escritos sobre la Biología y su Enseñanza. ISSN 2027-1034

Número Extraordinario. p.p. $40-54$

\begin{abstract}
Memorias del Primer encuentro ambiental Universidad, ambiente y
\end{abstract} sustentabilidad: experiencias y prácticas.

a la adquisición de competencias laborales que respondan a la realidad del contexto; en donde la comunidad educativa promueva una identidad cultural que respete, valore y reconozca sus prácticas, saberes y creencias de su región (Sánchez, 2007).

Reconociendo esta diversidad así como las problemáticas que presenta el contexto, se piensa en posibles soluciones para su cuidado y conservación, de ahí que el primer encuentro ambiental realizado por la facultad de Ciencia y Tecnología de la Universidad Pedagógica Nacional juega un papel importante permitiendo impartir conciencia, apropiación del territorio y adquisición de conocimientos biológicos y ecológicos, desde la educación ambiental, asumiendo compromiso y responsabilidad frente a las acciones y las valoraciones que se le dé al medio.

\title{
OBJETIVOS
}

Compartir la experiencia de práctica pedagógica integral a partir de las concepciones acerca de la pesca artesanal y el ecosistema de manglar de la comunidad educativa (INELPAC) en Bocas de Satinga (Nariño) como referente orientado hacia el fortalecimiento de la memoria biocultural y la enseñanza de la Biología en el contexto Afrocolombiano.

\section{ESPECÍFICOS:}

Develar los aportes de la práctica pedagógica integral desde el ejercicio investigativo en contexto en sus contribuciones posibles orientado hacia el fortalecimiento de la memoria biocultural y la enseñanza de la Biología en el contexto afrocolombiano. 
Bio-grafía. Escritos sobre la Biología y su Enseñanza. ISSN 2027-1034

Número Extraordinario. p.p. $40-54$

Memorias del Primer encuentro ambiental Universidad, ambiente y sustentabilidad: experiencias y prácticas.

Compartir la investigación realizada en el municipio de Bocas de Satinga en el primer encuentro ambiental que propicien reflexiones en torno al lugar de la educación ambiental en contextos bioculturalmente diversos.

\section{REFERENTES CONCEPTUALES}

Para el desarrollo de este artículo es necesaria una revisión documental y de porte teórico frente a las temáticas que constituyen esta experiencia, de manera que se tenga una visión amplia de cada uno de los conceptos.

Ecosistema de Manglar: Se reconoce como una zona compleja con alta diversidad, representado por plantas vasculares que han desarrollado una gran cantidad de adaptaciones (morfológicas, fisiológicas, entre otras) que les han permitido vivir en un ambiente intermareal, salino, dominado por la baja cantidad de oxígeno disuelto. Según Mejía Q. \& et. al (2014) cumplen una amplia serie de funciones ecológicas, entre las que se incluye,

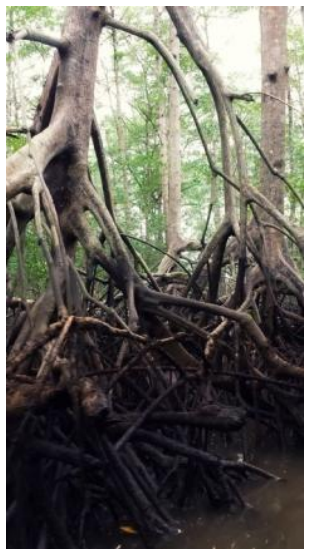
prevención de la erosión costera al facilitar la deposición del suelo; proveen comida y protección a mamíferos, peces y aves, constituyen el ambiente adecuado para la nidación, cría y alimentación de una amplia gama de animales y organismos acuáticos, entre otras.

Memoria Biocultural: Se cultiva en el pensamiento para la vida, que se expresa desde un sentido situado y localizado, su expresión se convierte en un campo de tensión donde se construyen, refuerzan, retan y transforman jerarquías, desigualdades y exclusiones sociales. La apropiación del territorio como espacio de la diversidad permite la memoria, que parte de la vida y regresa a la misma; desde esta consideración la memoria permite comprender el presente partiendo del pasado y dando luz en el futuro, en cuanto a las 
Bio-grafía. Escritos sobre la Biología y su Enseñanza. ISSN 2027-1034

Número Extraordinario. p.p. $40-54$

Memorias del Primer encuentro ambiental Universidad, ambiente y sustentabilidad: experiencias y prácticas.

prácticas, los conocimientos y las creencias que se encuentran vinculadas a los contextos y a su trasmisión de generación a generación como lo menciona Barrera \& Toledo (2009);

"Como los individuos y los pueblos, la especie humana también tiene memoria, y ésta permite develar las relaciones que la humanidad ha establecido con la naturaleza, soporte y referente de su existencia, a lo largo de la historia” (pág. 21).

Concepciones: Se parte de las concepciones de la comunidad, es decir sus representaciones o el pensamiento espontaneo que permite concebir la vida desde otras visiones; como lo menciona (Vilanova, S., García M. B. y Señoriño, O. 2007, pág. 6) como "unidades informativas que manejan y procesan las personas y dan cuenta de las construcciones mentales a través de las cuales captan el mundo" (pág. 11) esta descripción se acerca a lo planteado por Navarro, L. M. (2009), sin embargo, este autor se centra en el papel docente en cuanto al contexto escolar planteando que "se conforman por diversas experiencias relacionadas con la práctica educativa y dan lugar a estructuras cognitivas que permiten construir conocimiento cada vez más complejo" (pág. 15). Se asume también que para esta investigación los sujetos implicados no son objetos vacíos que pueden llenarse con conocimientos, sino son sujetos activos que construyen, organizan y estructuran conocimientos propios, producto del transcurso de su historia y de la enseñanza familiar y escolar, a través de sus experiencias y cotidianidades.

Pedagogía en contexto: Se parte de la importancia que tiene el contexto en cuanto al significado del conocimiento ya que la "educación no se puede entender al margen de un contexto, al margen de la sociedad. Una educación divorciada de su contexto carece de valor" (Borja M. s.f, pág. 32). Se dice 
Bio-grafía. Escritos sobre la Biología y su Enseñanza. ISSN 2027-1034

Número Extraordinario. p.p. $40-54$

\begin{abstract}
Memorias del Primer encuentro ambiental Universidad, ambiente y
\end{abstract} sustentabilidad: experiencias y prácticas.

entonces, que la pedagogía es contextualizada porque examina las prácticas educativas en su contexto y analiza sus vínculos políticos y sociales, (Borja M. s.f); así mismo su actuar implica transcender el sentido de la pedagogía y la didáctica en didácticas endógenas, localizadas y dinamizadas en y para el contexto (Peña M 2012). En concordancia a lo planteado este último autor da cuenta que la educación:

\begin{abstract}
"debería fundamentarse de manera consciente hacia un sentido de transformación y reafirmación de la cultura, consecuente con las particularidades y necesidades propias de los contextos socialesculturales, en línea con la formación de los valores sociales y el fortalecimiento de las identidades". (Peña M. 2012: Pág. 4)
\end{abstract}

Pesca Artesanal: Reconocer la fauna marina y elementos culturales dan cuenta de los conocimientos tradicionales de los habitantes sobre el territorio, siendo de gran importancia en la conservación biocultural del lugar. Por lo cual "La pesca artesanal es la realizada por pescadores en forma individual u organizada en empresas, cooperativas $u$ otras asociaciones con su trabajo personal independiente, con aparejos propios de una actividad productiva de pequeña escala y mediante sistemas, artes y métodos menores de pesca" (Gutierrez, 2010, pag. 20).

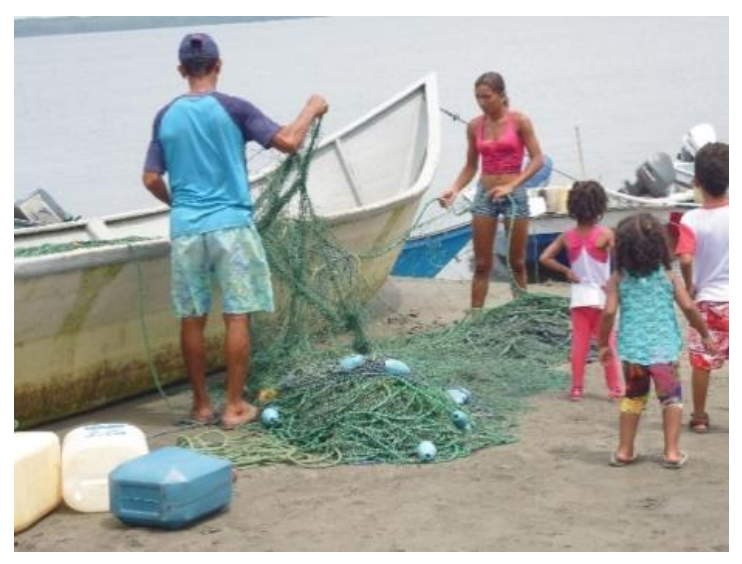

Imagen 4: Pesca artesanal. Foto tomada por: Angulo, K. (2015) 
Bio-grafía. Escritos sobre la Biología y su Enseñanza. ISSN 2027-1034

Número Extraordinario. p.p. $40-54$

Memorias del Primer encuentro ambiental Universidad, ambiente y sustentabilidad: experiencias y prácticas.

\section{MATERIALES Y MÉTODOS}

Esta investigación parte primordialmente de las realidades y particularidades del contexto y los actores que hacen parte del mismo, de tal manera que se basa en el paradigma hermenéutico-interpretativo con un enfoque cualitativo permitiendo enfatizar en técnicas de descripción, clasificación y explicación; donde hace parte algunos tipos de investigación como el etnográfico, antropológico, estudios de casos, etc. (Cerda, 1993); para este caso se aplicó el método etnográfico que como lo menciona Guber, R. (2001) es el "conjunto de actividades que se suele designar como "trabajo de campo", y cuyo resultado se emplea como evidencia para la descripción", mediante el uso de técnicas como la observación participante y la entrevista semiestructurada, teniendo en cuenta instrumentos como el diario de campo y medios audiovisuales (Fotografías, videos y grabaciones) que permitieron la recolección de la información de los estudiantes y actores locales del municipio. Los resultados obtenidos fueron organizados en matrices categoriales adaptadas de (Peña M, 2013) en las cuales de sistematizo la información para su posterior análisis y reflexión.

\section{RESULTADOS Y DISCUSIÓN}

Para este proyecto se trabajaron dos actores fundamentales, los estudiantes y la comunidad en general de Bocas de Satinga (pescadores, padres de familia, taladores de mangle, etc.). De acuerdo a esto se determinan las siguientes fases:

Fase I. Indagación: La práctica con los estudiantes inició el 23 de Julio del 2015, la cual tuvo una duración de 4 meses aprox., finalizando el 13 de noviembre del mismo año. El cronograma de actividades se clasificó en 4 
Bio-grafía. Escritos sobre la Biología y su Enseñanza. ISSN 2027-1034

Número Extraordinario. p.p. $40-54$

Memorias del Primer encuentro ambiental Universidad, ambiente y sustentabilidad: experiencias y prácticas.

categorías; la pre-contextualización como ejercicio de reconocimiento del municipio, la institución y el grado tercero y cuarto; la caracterización de la población, la socialización de la propuesta como el primer paso para iniciar con las actividades del proyecto, la cual se realizó mediante el dialogo y acercamiento con los

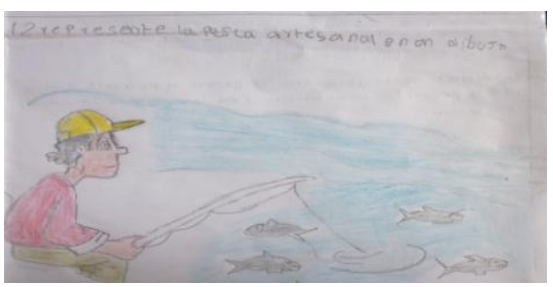

docentes, el rector y los estudiantes, quienes aceptaron la propuesta por su versatilidad y concordancia con el contexto y la institución; y por ultimo las acciones de indagación que fueron llevadas a cabo mediante el diseño y aplicación de guías didácticas adaptadas de (Peña M. 2013) con los estudiantes.

\section{Fase II. Caracterización:}

1. Actores Estudiantes. A partir de todo el trabajo realizado se construyeron matrices categoriales, las cuales generaron tres temáticas importantes que reúnen todo el significado de la memoria biocultural asociada al manglar y la pesca, las cuales son presentadas a continuación:

1.1. Conocimientos: Frente a esta temática se puede identificar que los estudiantes en su mayoría presentan un vasto conocimiento del mangle y de la pesca artesanal, debido a sus constantes interacciones con este ecosistema, que se dan por su cercanía al casco

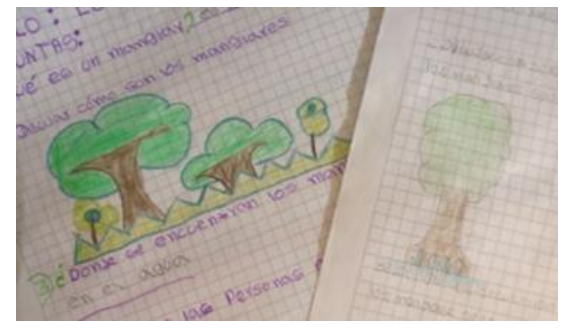
urbano y todo lo que la comunidad realiza desde el. Por otra parte, en cuanto a la pesca artesanal entienden la dedicación que requiere esta actividad además 
Bio-grafía. Escritos sobre la Biología y su Enseñanza. ISSN 2027-1034

Número Extraordinario. p.p. $40-54$

\begin{abstract}
Memorias del Primer encuentro ambiental Universidad, ambiente y
\end{abstract} sustentabilidad: experiencias y prácticas.

de los distintos instrumentos y procesos que se llevan a cabo para la extracción de los peces.

1.2. Prácticas: En el caso de esta temática los estudiantes poseen versatilidad a la hora de responder algunas de las preguntas que se plantearon, esto se da por el hecho de que mucho de los beneficios que posee la pesca y el manglar son de gran importancia para el sustento de la comunidad. Algunas de las prácticas mencionadas fueron: La madera del mangle que es muy apreciada por su dureza y resistencia al ataque de insectos o factores como la humedad, también como zona de crianza y refugio, como pesquerías ya que gran parte de los peces necesitan vivir en estuarios durante una parte de su vida, debido a que son ambientes con gran cantidad de nutrientes y da protección que les suministra las raíces del mangle. Además, la pesca artesanal ha permitido generar conocimiento entre generaciones, inculcándole gran valor como actividad económica, así como cuidado y conservación de los mismos organismos de los cuales la comunidad se provee de alimento.

1.3. Creencias: En esta temática, con los estudiantes se abrieron varios espacios de dialogo y escritura, de historias, cuentos, leyendas y algunos saberes que ellos poseen en relación al manglar y la pesca artesanal. El resultado de estas actividades se presentaba desde experiencias propias asociadas a algún tipo de acercamiento al ecosistema o también a la actividad laboral que realiza algún familiar, por ejemplo:

“Un día una vez yo veía unos árboles muy bonitos, grandes y con raíces por fuera del agua, muy bonitos, al pasar el tiempo llegaron unas familias que llegaron al pueblo y lo contaminaron mucho, al pasar el tiempo los árboles se murieron y se contamino todo. Fin." (Daniel Vergara, 2015). 
Bio-grafía. Escritos sobre la Biología y su Enseñanza. ISSN 2027-1034

Número Extraordinario. p.p. $40-54$

Memorias del Primer encuentro ambiental Universidad, ambiente y sustentabilidad: experiencias y prácticas.

"La pesca se hace con una caña de pescar y se puede poner cualquier clase de carne. Se tiene que hacer en un ligar cerca del rio. Se pesca cualquier tipo de marisco cerca al rio. La mayoría pescan con cañas de pescar, pero también se pescar con palos o varillas" (Grupo Gualajo, 2015)

2. Actores locales. Los diferentes actores que se presentaron en la investigación dan cuanta de todas las interacciones, prácticas, creencias y saberes que tienen la comunidad de Satinga sobre el manglar y la pesca artesanal. Se puede identificar que desde la población se presenta un gran acercamiento a este ecosistema que en su mayoría se reconoce por los beneficios que provee (Madera, pesca, zona de crianza, entre otras.).

Con los estudiantes, maestros y padres de familia se presenta un similaridad hacia la constante preocupación de cuidar los mangles, la actividad pesquera y los saberes ancestrales evitando actividades como la tala y el daño de rio por desechos tóxicos; sin embargo, aunque se presentan soluciones muy innovadoras se tiende a buscar cierta culpabilidad no en ellos sino en el otro sujeto. Para el caso de pescadores y taladores de mangle su pensamiento hacia el manglar se encuentra más orientado a sus necesidades alimenticias, familiares, de salud, económicas, entre otras; no se presenta un sentido de preocupación hacia la contaminación o extinción de los recursos, sino solo al hecho cumplir cierta labor y generar ganancias.

Concluyendo así, se puede decir que pensar y evocar memorias hacia el manglar es entrar en pensamientos muy diversos, los cuales dan cuenta de la situación 0 el presente en el que este el ecosistema actualmente. Las creencias, saberes y prácticas que muchos adultos y niños comentan sobre este ecosistema son el fortalecimiento de su cultura y la idenficación que ellos 
Bio-grafía. Escritos sobre la Biología y su Enseñanza. ISSN 2027-1034

Número Extraordinario. p.p. $40-54$

Memorias del Primer encuentro ambiental Universidad, ambiente y sustentabilidad: experiencias y prácticas.

tienen con su territorio, el cual necesita de grata valoración, cuidado y respeto desde ellos, desde las escuelas y desde el país.

\section{CONCLUSIONES}

Para esta investigación surgieron algunas conclusiones como:

- Las concepciones que poseen los actores vinculados a esta investigación están muy relacionadas con el uso directo o indirecto que estos hacen con el mangle y la pesca artesanal, por lo que es necesario que en las escuelas se planteen estrategias pedagógicas que busquen la construcción de valores hacia el cuidado y preservación de su ambiente.

- Pensar en estos contextos permite comprender y analizar el lugar de la educación ambiental en estos espacios, debido a que, observando las problemáticas ambientales, es necesario que se planteen estrategias didácticas para la conservación de sus ecosistemas y prácticas ancestrales, de manera que la comunidad pueda tener un uso sustentable con su ambiente.

- Compartir experiencias como esta, es algo enriquecedor para la formación profesional y personal de los maestros en Biología ya que permite dialogar y escuchar otros puntos de vista frente a estos conocimientos que emergen de la investigación.

- Es necesario que como maestros en formación de biología se sigan realizando prácticas en diversos lugares de nuestro país, por todo el conocimiento que se puede compartir y adquirir ya que el docente "no es visto como educador de los otros sino más bien quien se educa en la interacción con los otros" (Peña M, 2012). 
Bio-grafía. Escritos sobre la Biología y su Enseñanza. ISSN 2027-1034

Número Extraordinario. p.p. $40-54$

Memorias del Primer encuentro ambiental Universidad, ambiente y sustentabilidad: experiencias y prácticas.

\section{BIBLIOGRAFÍA}

Araujo L. (1997) Somos seres con tiempo y con memoria. Formación social campesina-resiembra-. Centro de Investigación y Educación Popular (CINEP). Bogotá, Colombia.

Barrera \&. T. (2009). La memoria biocultural. La importancia ecológica de las sabidurías tradicionales. Editorial Icaria.

Borja M. (s.f.). La pedagogía crítica y la contextualización de la enseñanza. Revista eureka Edición N. 4. España

Cerda, H. (1993). Los elementos de la investigación: como reconocerlos, diseñarlos y construirlos. Abya Ayala, Quito

Comunidad Educativa Institución Educativa Comercial Litoral Pacífico (2014) Proyecto Educativo Institucional hacia la calidad educativa. Bocas de Satinga, Municipio Olaya Herrera. Departamento de Nariño.

Comunidad Educativa Institución Educativa Comercial Mixto Litoral Pacífico (1997) Proyecto Educativo Institucional, hacia la calidad educativa (ILIPAC 2002)

Cuesta D. \& Córdoba A. (2004) Descubriendo mi Identidad, Cátedra Afrocolombiana. $4^{\circ}$ y $5^{\circ}$ grado Básica Primaria. Corporación Identidad Cultural. Bogotá, Colombia.

Gutiérrez F. P. (2010). Los recursos hidrobiológicos y los recursos pesqueros continentales de Colombia. Instituto de Investigación de Recursos Biológicos Alexander von Humboldt. Bogotá.

Guber, R. (2001). La etnografia, Metodo, campo y reflexividad. Bogota: Enciclopedia Latinoamericana de sociocultura y comunicacion. Grupo editorial norma.

Mejía Q., Molina Jiménez, M.P., Sanjuan Muñoz, A., Grijalba Bendeck, M. \& Niño Martínez, L.M. (2014). Bosque de manglar, un ecosistema que debemos 
Bio-grafía. Escritos sobre la Biología y su Enseñanza. ISSN 2027-1034

Número Extraordinario. p.p. $40-54$

Memorias del Primer encuentro ambiental Universidad, ambiente y sustentabilidad: experiencias y prácticas.

cuidar. Universidad Jorge Tadeo Lozano, Instituto Colombiano de Desarrollo Rural. Cartagena D. T. 27p.

Navarro, L. M. (2009). CONCEPCIONES DE LOS ESTUDIANTES DE GRADO OCTAVO SOBRE EL CONCEPTO DE SEMEJANZA. Presentado como requisito parcial para optar al título de Magíster en Docencia e Investigación Universitaria.UNIVERSIDAD SERGIO ARBOLEDA .

Peña, M.T. (2013). Construcción de subjetividades Políticas de niñas, niños y jóvenes Quechuhablantes, en el contexto de la experiencia "comunidades andinas Educativas" en los Andes centrales del Perú: un referente de educación particularizado y diverso. Trabajo de grado para maestría en investigación. Universidad Pedagógica Nacional. Bogotá.

Vilanova \& Silvia L., García M., \& Orlanda S., (2007). Concepciones acerca del aprendizaje: diseño y validación de un cuestionario para profesores en formación. Revista Electrónica de Investigación Educativa. Vol. 9, Núm. 2. Buenos Aires, Argentina. 